\title{
Primary School EFL Teachers' Attitudes towards Creativity and Their Perceptions of Practice
}

\author{
Nowreyah A. Al-Nouh ${ }^{1}$, Muneera M. Abdul-Kareem ${ }^{2} \&$ Hanan A. Taqi ${ }^{1}$ \\ ${ }^{1}$ English Department, College of Basic Education, Kuwait City, Kuwait \\ ${ }^{2}$ College of Education, Kuwait University, Kuwait City, Kuwait \\ Correspondence: Nowreyah Al-Nouh, English Department, College of Basic Education, Al-Ardhiya, Block 1, Str. \\ Mohammed Ibn Al-Qasim, facing Jaber Stadium, Building 9, Office No. 59, Kuwait City, Kuwait. Tel: \\ 965-9911-2672. E-mail: nowreyah2008@hotmail.com
}

Received: June 1, 2014 Accepted: July 14, 2014 Online Published: August 14, 2014

doi:10.5539/elt.v7n9p74 URL: http://dx.doi.org/10.5539/elt.v7n9p74

\begin{abstract}
Teachers perform an important job by encouraging creativity in their lessons and among their pupils. Thus, the present study aims to examine primary school EFL teachers' attitudes towards creative thinking and their perceptions of what goes on in the classroom. Participants were 434 female primary school EFL teachers, chosen randomly, teaching all grade levels from six educational zones in Kuwait, namely Al-Asema, Hawalli. Al-Farwaniyah, Mubarak Al-Kabeer, Al-Ahmadi and Al-Jahra for the year 2014-2015. The study used a descriptive survey research design using Likert's five-point scale distributed into three categories: demographic information, teachers' attitudes towards creative thinking and teachers' perceptions of their practice. To triangulate the data, a focus group interview was employed along with an analysis of samples of exam papers. Independent variables measured were age, nationality, degree, major, educational zone, teaching experience and in-service training. Results showed teachers' attitudes and perceptions were high. Significant differences were shown for age, major, educational zone, teaching experience and in-service training. Implications as well as recommendations for future research were discussed.
\end{abstract}

Keywords: teachers' attitudes, teachers' perceptions, creative thinking, EFL teachers' attitudes

\section{Introduction}

The role that creativity plays in education has been discussed extensively (Craft, 2006; Cachia \& Ferrari, 2010; Glaveanu, 2011; Humes, 2011; Rinkevich, 2011; Beghelto \& Kaufman, 2013). Some believe it is more suitable for primary school children than for older students. Indeed, there seems to be a consensus that creativity is more applicable to primary school children (Duffy, 2003; Turner, 2009; Smears, Cronin, \& Walsh, 2011). Some claim that children's spontaneous creativity diminishes with age (Grainger, Barnes, \& Scoffham, 2004). In England, for example, creativity is included as an aim in the curriculum particularly in primary education (Craft, 2001). Claxton, Pannells, and Rhoads (2005) explored how divergent thinking and divergent feeling (factors supporting creativity) developed in 25 pupils in grades 4,6 , and 9. Results showed that divergent thinking does not significantly increase into adolescence, but divergent feelings such as motivation and personality do. This suggests that creativity in general and creative thinking in particular needs to be developed from the early stages of life (Craft, 2000; Duffy, 2003; Turner, 2009).

Many definitions were given for creativity (National Advisory Committee on Creative and Cultural Education, 1999; Craft, 2001; Mason, 2003; Mumford, 2003; Creative Partnership, 2007; Cachia \& Ferrari, 2010). However, the literature review reveals that there is no consensus as to a definition for creativity. For example, some researchers believe that to call something creative, it has to be new and of great value (Dacey \& Lennon, 2000; Mason, 2003; Glaveanu, 2011). This definition applies to talented people and is relevant to neither education nor all pupils. Others talked about everyday creativity as the implementation of knowledge in an unusual way to reach an objective (Craft, 2001). 'Everyday creativity' implies the use of natural skills of ordinary people to find solutions to everyday situations in an unusual way, endure difficulties, and think of other ways to handle daily routines (Ivcevic 2007; Cachia \& Ferrari, 2010). This definition is more relevant to education and to this study understanding that learners come with different abilities, and all of them are creative in their own ways. With this broad definition, creativity applies to all domains of knowledge (Grainger \& Barnes, 2006) - not only arts, 
science, and music — and to all pupils.

Understood this way, creativity is a skill needed in order to be efficient in a modernized world. In a society in which communication technologies such as the internet and mobile phones are widely used, creative thinking becomes the path to development and prosperity (Craft, 2001; Schacter, Thum, \& Zifkin, 2006). It is therefore the task of the educational system to provide students with the essential skills to adapt, to think independently, and to work with others.

Policy makers and educationalists have been preoccupied trying to find out the best ways to teach students. Today, "Communicative Language Teaching" and "Task-Based Teaching" are the most widely used methods in the field of language teaching as they emphasize creativity through authentic communication and the exchange of ideas in group work activities.

Nevertheless, education in most countries either does not include creativity as one of its objectives or fails to train teachers on how to implement it. Added to that is the fact that teachers in most countries are under pressure to cover prescribed material imposed on them by the English Inspectorate (at the MOE responsible for supervising teachers). In addition, the exam-oriented system adopted by these countries has forced teachers to "teach to the test" (Jenkins, 2000 in Turner, 2013).

Some educationalists seem not to have realized that teachers are the implementers of the curriculum (Soh, 2000; Wyse \& Spendlove, 2007; Leung, 2008). Teachers play a crucial role in fostering or hindering learners' creative potential (Wyse \& Spendlove, 2007). General attitudes reflect teachers' beliefs and have a powerful effect on their practice. Understanding teachers' attitudes towards creativity and their perception of their practice is believed to be essential for the implementation of creativity (Leung, 2008), because outlooks towards creativity correlate with how often creativity is emphasized in the classroom (Craft, 2001). Whether educationalists and policy makers included creativity as an objective, the fact that there are obstacles to its implementation begs further research (Craft, 2001; Turner, 2009; Cachia \& Ferrari, 2010; Constantinides, 2010; Rinkevich, 2011; Cheung, 2012). If setting objectives is considered a step towards the implementation of creativity, then discovering teachers' attitudes and practice is the next. In addition, teacher educators must understand teachers' attitudes and their practices in order to provide them with training programs that reinforce their practices in relation to their attitudes. Teachers further need to be aware of their own attitudes and how they match with their practices. Thus, this study intends to establish primary school EFL teachers' attitudes towards creativity and their perceptions of practice.

\section{Teaching English at Primary School in Kuwait}

To keep up with educational reform, the Ministry of Education (MOE) presented English as a subject in primary schools in Kuwait in 1993 (International Bureau of Education of UNESCO, 2010/11). The reason for introducing English early was the fact that language instruction at this stage would give pupils more time to learn English (Brewster, Ellis, \& Girard, 2004).

Education in Kuwait is mandatory and free; it is a right of all citizens. One of the objectives of education is developing the education system to provide young people who can participate actively in their society and equip them with lifelong learning and analytic thinking.

Primary education starts at age six. According to the Ministerial Decree No. 76 of 2003, primary education lasts for five years followed by four years in intermediate and finally three years in secondary education. The MOE is responsible for schools while the Ministry of Higher Education is responsible for higher education. Because of the demand for more schools in different residential areas, there became a need for educational zones. In the 1980s, five educational zones were established: Al-Asema, Hawalli, Al-Farwaniya, Al-Ahmadi, and Al-Jahra. In 1999, Mubarak Al-Kabeer was added. The zones are responsible for evaluating school performance (International Bureau of Education of UNESCO, 2010).

Teaching English at the primary stage aims to familiarize pupils with the fundamentals of the language and adapt them to the English sound system. The goal is to allow them to use English as another means of communication (ELT General Supervision, 2010-11).

English is a subject treated similarly to other subjects. It is taught five times a week (i.e., 151 periods per year) for 40 minutes a day. Pupils are evaluated four times a year with a break of eight weeks between evaluations (ELT General Supervision, 2010-11).

\section{Statement of the Problem}

Although perceived by most teachers as necessary for developing thinking skills in children, helping them to 
become independent, and solving problems, creative thinking is not encouraged by most teachers. Makel (2009 in Rinkevich, 2011) called this discrepancy a "creativity gap". One reason for this lack could be that teachers have been pushed to 'teach to the test', and tests focus on factual knowledge and rote memorization, not creativity (Rinkevich, 2011). More interest has been placed on achieving high grades and passing formal tests and less on equipping pupils with lifelong skills like creative thinking (Cheung, 2012). Also, time constraints apply to teachers who are often overloaded with a huge curriculum that they need to finish in a short time (Turner, 2009). Most importantly, many teachers' harbor a belief that young children are unable to think productively, which has resulted in teachers emphasizing rote-learning to the neglect of problem solving and creative thinking (Torrance, 1983 in do Souza, 2000). Added to this is the fact that most teachers do not know how to foster creative thinking in pupils as a result of lack of training.

\section{The Literature Review}

Research has indicated that classroom creativity is often discouraged (Freund \& Holling, 2008). Although teachers say that they promote creativity, they do not promote creative behaviors. Teachers are preoccupied with dispensing prescribed curricula that they barely have time to cover in order to prepare pupils for summative traditional written tests in which the focus is mainly on evaluating grammar and vocabulary. Indeed, the literature has listed some reasons that hinder the progress of creativity, such as teachers providing all explanations and asking and answering questions, shortage of time, use of traditional teaching approaches, whole class teaching, rote learning, and a classroom climate that is full of fear and criticism (Turner, 2009; Constantinides, 2010; Cheung, 2012; Turner, 2013).

The literature has also discussed ways of fostering creative thinking in pupils, such as using open-ended questions, making connections between content material and real life, allowing pupils to learn and discover by themselves, using technology, making pupils feel safe and free to state their own opinions, encouraging pupils to work in groups and using varied exercises and experiential learning (Cachia \& Ferrari, 2010; Rinkevich, 2011; Cheung, 2012).

Research on creativity has been mainly theoretical and emphasizes the qualities of creative teachers (Craft, 2001; Rinkevich, 2011; Cheung, 2012), factors that hinder creative thinking (Cheung, 2012; Beghelto \& Kaufman, 2013; Turner, 2013), factors that foster creative thinking (Claxton et al., 2005; Cachia \& Ferrari, 2010; Zarillo, 2012), the importance of creative thinking (Grainger \& Barnes, 2006; Smears et al., 2011; Zeteroglu et al., 2012), the assessment of creativity (Craft, 2001; Black, Harrison, Lee, Marshall, \& William, 2004), and examples of creative activities (Beghelto \& Kaufman, 2013; Turner, 2013). A few studies have recently discussed teachers' perceptions of creativity. For example, to explore teachers' and students' beliefs about creativity in the classroom in England, Denise do Souza (2000) found that pupils had enough materials to foster creativity in their classrooms. Although teachers said that they have enough occasions to promote creativity in the classroom, their responses reflect a lack of training in how to inspire creativity in their students.

Teachers' practices were also studied to explore elements of creative teaching by observing them in the UK teaching three different subjects: geography, music, and English (Grainger et al., 2004). Results revealed that teachers did employ creativity in their teaching methods. For example, teachers use multi-model teaching approaches, open-ended questions, audio-visual aids, and learner-centered teaching. Students were resultantly motivated and challenged to engage with the subject matter.

Teachers' perceptions of their practices have gained importance recently as Turner (2013) attempted to discover how primary and secondary school ESL teachers in England use creativity within their teaching. Results showed primary school teachers provided more emotional support for frustrated pupils and more time to look at pupils' work - factors known to foster creativity in students. Constraints mentioned were the extra time needed to cover prescribed content and lack of creativity training. Overall, teachers showed positive attitudes towards creativity and reported that they provided creative teaching environments.

Other studies compared teachers' beliefs with their actual practices. Surprisingly, these studies found discrepancies between teachers' beliefs and their practices (Al-Nouh, 2008; Turner, 2009; Cachia \& Ferrari, 2010; Cheung, 2012; Roy \& Carter, 2013). For example, Turner (2009) investigated the way teachers in England understand and implement creative teaching at key stage 3 (i.e. three years of schooling, year 7, $8 \& 9$ ). She found that teachers use creative tasks in many lessons. For example, teachers used cooperative tasks, took pupils' questions seriously, and provided a rich resource environment. Turner's study also showed pupils enjoying their lessons. However, some creative strategies, such as encouraging pupils to learn independently, promoting self-evaluation in pupils, using open-ended questions, and letting pupils discover topics by themselves were hardly employed. 
Using an online survey, Cachia and Ferrari (2010) solicited the perceptions of 12,893 ESL teachers of different school levels from 32 countries in Europe to find how teachers perceive creativity and how they foster it in their teaching. Results showed that teachers believe creativity can be implemented in all subjects. Nevertheless, there was a discrepancy between teachers' opinions of creativity and their practices. Although teachers encouraged creativity, they did not foster it in their classrooms. Reasons, as reported by teachers, were formal testing, lack of resources, and lack of training in how to foster creativity in the classroom.

Similarly, to investigate whether primary school ESL teachers' perceptions of creativity match their practice, Roy and Carter (2012) found that teachers in the US were able to recognize creative activities $79 \%$ of the time, but they put only $38 \%$ of creative activities into practice. Creative teaching practices do not occur frequently in the classroom, while those that hinder creativity, such as standardized testing and statewide curriculums, occur more often. Although teachers showed knowledge and valued creativity, creative activities were rarely applied in their classrooms.

From ESL to EFL in Hong Kong, Cheung (2012) strove to match elementary teachers' beliefs about creative teaching with their practices. Results showed that teachers believed in the factors that promote creativity such as using open questions and promoting free expression and the exchange of ideas. However, classroom observation has shown teachers use of close-ended questions and teacher-centered teaching. Teachers gave direct instructions and explanations, asked questions, and elicited answers instead of allowing pupils to express their ideas freely. Teachers overall, lacking proper training, did not encourage creative thinking in their teaching.

Regarding the role of independent variables, a few of the previous studies tried to find whether there was an effect of age and experience on teachers' perceptions of creativity. For example, in Turner's study above (2013), no effect was found for age and experience on teachers' perceptions of creativity. In contrast, Cachia and Ferrari (2010) found that teachers under the age of 25 who had been teaching for less than a year fostered creativity more than the others. On the other hand, do Souza (2000) did not find a difference for age and experience regarding teachers' perceptions of creativity in the classroom.

The discrepancies in the results of the previous studies might be because some studies looked at perceptions of creativity while others looked at practice, or it might be the result of sample size. On the other hand, as seen above, very few studies investigated the effect of variables, such as age and experience. Other variables, such as degree, major, nationality, educational zone, and in-service training, were under-researched; a few studies aspired to look at teachers' perceptions of their practices. In addition, most of the studies above compared teachers' beliefs with their actual practices. These studies and their results suggest that teachers' attitudes towards creativity and teachers' perceptions of their practices need further investigation.

Furthermore, while previous research reports that there is a discrepancy between teachers' beliefs and their perceptions of practice, relevant studies on the issue are scant and findings are inconclusive. Added to that, is the fact that the majority of the previous studies were conducted in an ESL context, rather than an EFL context. Also, research on creativity in the field of language learning or that done in an Arab context is scarce compared with that done in the US, England, Europe, and Asian countries. With these concerns in mind, the present study aims to explore teachers' attitudes and perceptions of their practice on creative thinking hoping to add to the existing amount of research. Thus, this paper will examine the following research questions:

1) What kind of attitudes do primary school EFL teachers have towards creativity?

2) What kind of perceptions do primary school EFL teachers have about their practices?

3) Do teachers differ in their attitudes and perceptions of practice in relation to their age, nationality, degree, major, teaching experience, in-service training, and educational zone?

\section{Method}

\subsection{Participants}

Participants were 434 female primary school EFL teachers chosen in a random way from 1526 female EFL primary school teachers (i.e., $28.4 \%$ of the whole population) from 48 primary schools ( 8 schools were randomly selected from every one of the 6 educational zones in Kuwait). Teachers taught English to all grade levels (1-5). Of the 580 teachers, 434 (i.e., $75 \%$ ) returned completed questionnaires. The majority of the respondents (91.7\%) were between 21-40 years, while only $8.3 \%$ were 41 and older. Knowing that almost all teachers $(\mathrm{N}=417)$ held a Bachelor degree, this variable was left out of the analysis. The demographic characteristics of the participants in this study are representative of the teacher body of EFL female primary school teachers (Table 1). 
Table 1. Distribution of sample

\begin{tabular}{|c|c|c|}
\hline Independent Variables & No. & $\%$ \\
\hline \multicolumn{3}{|l|}{ Age } \\
\hline $21-30$ & 174 & 40.1 \\
\hline $31-40$ & 224 & 51.6 \\
\hline $41+$ & 36 & 8.3 \\
\hline Total & 434 & $100 \%$ \\
\hline \multicolumn{3}{|l|}{ Nationality* } \\
\hline Kuwaiti & 148 & 34.3 \\
\hline Non- Kuwaiti & 283 & 65.7 \\
\hline Total & 431 & $100 \%$ \\
\hline \multicolumn{3}{|l|}{ Major* } \\
\hline Primary & 263 & 60.7 \\
\hline Middle \& High School & 24 & 5.5 \\
\hline General English & 146 & 33.7 \\
\hline Total & 433 & $100 \%$ \\
\hline \multicolumn{3}{|l|}{ Educational Zone* } \\
\hline Al-Asema & 68 & 15.8 \\
\hline Hawalli & 71 & 16.5 \\
\hline Farwaniyah & 81 & 18.8 \\
\hline Mubarak Al-Kabeer & 64 & 14.8 \\
\hline Al-Ahmadi & 69 & 16.0 \\
\hline Al-Jahra & 78 & 18.1 \\
\hline Total & 431 & $100 \%$ \\
\hline \multicolumn{3}{|l|}{ Teaching Experience* } \\
\hline 5 and less & 143 & 33.2 \\
\hline $6-10$ & 218 & 50.6 \\
\hline $11+$ & 70 & 16.2 \\
\hline Total & 431 & $100 \%$ \\
\hline \multicolumn{3}{|l|}{ In-service Training* } \\
\hline No & 289 & 66.9 \\
\hline Yes & 143 & 33.1 \\
\hline Total & 432 & $100 \%$ \\
\hline \multicolumn{3}{|l|}{ Degree } \\
\hline Diploma & 11 & 2.5 \\
\hline Bachelor & 417 & 96.1 \\
\hline Master & 6 & 1.4 \\
\hline Total & 434 & $100 \%$ \\
\hline
\end{tabular}

*Refers to variables where some participants did not give information; therefore, they were left out of the analysis. 


\subsection{Instrument}

The instruments used to collect descriptive data included a questionnaire consisting of 41 items, an interview, and an analysis of exam papers. The questionnaire was developed after a comprehensive review of the literature on creative thinking (Turner, 2009; Soh, 2011; Zeteroglu et al., 2012; Roy, 2013; Roy \& Carter, 2013; Turner, 2013).

The questionnaire was further categorized into three major parts. The first part of the questionnaire was established to obtain knowledge about the demographic profile of the participants, including age, nationality, major, degree, in-service training, teaching experience, and educational zone; whereas the second part consisted of 19 statements and aimed to discover teachers' attitudes towards creative thinking. The final part of the questionnaire consisted of 20 statements aimed to explore teachers' perceptions of their own practices. Two open-ended questions were included to probe deeper into teachers' attitudes and practices. Question 40 requested teachers to choose from a list of five the one(s) that they thought might prevent creative thinking in pupils (lack of in-service training, traditional tests, time constraints, rote learning, and lack of resources); they were further provided a space in case they wanted to add other reasons. Question 41, on the other hand, asked teachers whether they implemented creative thinking in their classes, and if teachers said 'yes', they had to provide an example of a creative-thinking activity.

A five-point Likert-type scale was used to write the items of the questionnaire. For questions 1-19, the scale employed the following: strongly disagree $=1$, disagree $=2$, neutral $=3$, agree $=4$, and strongly agree $=5$ ). For questions 20-39, the following scale was used: never $=1$, rarely $=2$, sometimes $=3$, usually $=4$, and always $=5$. A Cronbach Alpha coefficient was calculated to establish reliability of the scale, which was found to be 0.86 , demonstrating a high reliability.

To probe deeper into teachers' attitudes and perceptions, a group interview of 19 primary school principals, and 149 primary school EFL teachers from 19 schools chosen randomly from three educational districts (Al-Asema, Al-Farwaniyah and Al-Ahmadi) was used. Five questions were designed to explore teachers' attitudes and perceptions of their practices in creative thinking. Question 1 asked the participants about their opinions concerning the current curriculum and whether their methods encouraged creative thinking, while question 2 asked whether they believed creative thinking was a privilege of all pupils, or some, and why. As for question 3, teachers were asked to report how they encouraged creative thinking in their classrooms, while principals were asked to report using their observations gained from their visits to classrooms, whether all teachers encouraged creative thinking and if not, why not. Question 4, however, asked participants to indicate the environment suitable for encouraging creative thinking in pupils. And question 5 asked if they believed there was a need for training courses about how to foster creative thinking in pupils.

Finally, an analysis of exam papers was used to examine the kinds of questions used and whether they stimulated creative thinking in pupils.

\subsection{Procedure}

The questionnaire items were re-examined by two professors from the English department to ensure comprehension and clearness of items. Their comments were used to revise the questionnaire. Afterwards, a written permission was obtained from the Education Research Center at the MOE to be submitted to the six educational zones where further written permissions were made to enable the researcher to collect data from schools. Following that, the questionnaire was piloted on 35 primary school EFL teachers (not included in the sample) to further check comprehension and clarity of the items. As a result, changes were made for clarity and precision. Accordingly, 580 questionnaires were administered during the spring semester of the academic year 2014/2015, but only 434 were returned.

Regarding the interviews, teachers $(\mathrm{N}=149)$ were interviewed in groups while school principals $(\mathrm{N}=19)$ were interviewed individually. Group interviews were used for many reasons, one of which was to enhance data interpretation and encourage deeper discussion and insight that would be impossible to obtain with other methods. To ensure accuracy, all interviews were done by the researcher.

To triangulate the data, an analysis of samples of exam papers was conducted to find out whether they promote creative thinking in pupils. The researcher managed to collect them from teachers during school visits as well as from the ELT Inspectorate at the MOE.

\section{Statistical Analysis}

To analyze the data, percentages, means, and standard deviations were calculated to assess primary school EFL teachers' attitudes towards creative thinking and their perceptions of practice. In addition, t-tests for significant 
differences were employed to examine similarities and differences between Kuwaiti and non-Kuwaiti teachers and those who took in-service training and those who didn't in attitudes and perceptions. A one-way ANOVA test for significant differences was used to compare the different groups in age, major, educational zone, and teaching experience in attitudes and perceptions.

For ease of analysis, subjects' attitudes and perceptions were divided into three parts: high, medium, and low. Thus, means were estimated as the following:

(From 1-2.33) shows a low value mean

(From 2.34-3.66) shows a medium value mean

(From 3.67-5.00) shows a high value mean

The open-ended questions (40-41) were grouped according to emergent themes and were analyzed quantitatively and qualitatively.

\section{Results and Discussion}

In answer to the first research question, the results in Table 2 show that overall, teachers' attitudes and perceptions of their practices regarding creative thinking were high: $\mathrm{M}=3.71$ and $\mathrm{M}=4.09$, respectively. Teachers seemed willing to foster creative thinking in their classrooms and perceive themselves as doing so. These results are similar to Turner's (2013) study, where teachers reported providing creative teaching environments, and Roy and Carter's (2013) study, where 67\% of respondents believed that their classroom was one that fostered creativity.

Table 2. General means and standard deviations for teachers' attitudes and perceptions of practice

\begin{tabular}{llll}
\hline Factors & M & SD & Rank \\
\hline Teachers' Attitudes & 3.71 & .386 & High \\
Teachers' Perceptions of Practices & 4.09 & .431 & High \\
\hline
\end{tabular}

The means and standard deviations were established for teachers' attitudes and perceptions of their practices according to Table 2 .

As shown in Table 3, statement 1 got the highest score $(\mathrm{M}=4.52)$, showing that the majority of teachers $(59 \%)$ strongly agreed that creative thinking is necessary and needs to be developed in schools. This is consistent with other studies (Roy \& Carter, 2013; Turner, 2013). Teachers further believed that teacher training is a prerequisite in order to learn how to develop creative thinking skills in pupils.

Although the overall attitudes of teachers towards creative thinking showed a high level, teachers acknowledged some hindrances to the progress of teaching creative thinking. For instance, many teachers (39\%) believed that portfolios do not enhance pupils' creativity. This is consistent with the results of a study done by the researcher on EFL primary school teachers' attitudes towards alternative assessment, in which teachers' attitudes were shown to be high (Al-Nouh, 2014); nevertheless, Cachia and Ferrari (2010) listed portfolios as one of the factors that promote creative thinking in pupils. The reason behind this inconsistency is that when portfolio assessment was implemented in Kuwait, pupils were allowed to pass automatically to the next grade level, thus they were not motivated to study and parents did not care, which resulted in pupils' low performance in writing and reading skills (Al-Nouh, 2014).

Another factor is teachers' beliefs that developing creative thinking adds to their workload (statement 6). This is also in line with Turner's study (2013), which reported that teachers were under pressure to cover content and thus did not have time for creative activities. However, in a previous study Turner (2009) reported from a classroom observation that teachers do use creative tasks in their lessons; however, she observed only 10 teachers who employed a few creative strategies while ignoring others. Teachers (32\%), in the present study further acknowledged that rote learning is necessary to pass exams, and Cheung (2012) found in a classroom observation that teachers were concerned with factual information and rote learning. This reflects a culture of learning in which teachers help pupils memorize content to be able to reproduce it in exams (Rinkevich, 2011; Sadeqhi, 2014). As Beghetto (2005) reported, assessment affects the way teachers teach. This is justified by the responses to statement 9 , in which most teachers agreed (44\%) that they 'taught to the test' when tests focus on grammar and vocabulary. 
Table 3. Means and standard deviations for teachers' attitudes towards creative thinking

\begin{tabular}{lllll}
\hline No. & Statement & M & SD & Rank \\
\hline 1 & Creativity is an essential skill to be nurtured in schools. & 4.52 & .653 & High \\
2 & Teacher training is important to foster creativity in education. & 4.31 & .899 & High \\
3 & Portfolios enhance pupils' creativity. & 2.44 & .189 & Medium \\
4 & Creativity can be assessed. & 3.38 & .967 & Medium \\
5 & Creativity can be taught. & 3.81 & .831 & High \\
6 & Teaching creativity is an additional work load. & 3.49 & .058 & Medium \\
7 & Rote learning is necessary to pass exams. & 3.31 & .348 & Medium \\
8 & Independent learning enhances creative thinking. & 4.10 & .834 & High \\
9 & Teaching to the test doesn't leave time for creative activities. & 4.20 & .894 & High \\
\hline
\end{tabular}

The means and standard deviations were established for teachers' attitudes towards creative thinking, according to Table 3 .

While teachers continued to show generally positive attitudes in Table 3; Table 4 lists the factors that hinder creative thinking in pupils. For example, more than half the teachers $(52 \%)$ restated their dissatisfaction with the time allotted to finish the curriculum $(\mathrm{M}=4.31)$. This was also reported by other studies, for example, Do Souza (2000) reported that teachers mentioned the long curriculum and lack of time as some of the inhibiting factors. This might suggest that teachers are implementing a few creative activities in their classrooms, as Roy and Carter (2013) found in their study indicating that teachers put only $38 \%$ of creative activities into practice. This is further reported by other teachers elsewhere (Turner, 2013). Makel (2009) called this discrepancy between the perceived value of creativity (statement 1) and the inability to apply it (statement 10) the 'creativity gap'. And Cheung (2012) argued that creativity does not depend merely on issuing policy documents, but also on the way it is actually practiced in the classroom.

In addition, a large number of teachers (52\%) reported that there was a need for questions that encouraged creative thinking in exams. This might suggest that exams lack questions that promote creative thinking, which was supported by exam analysis. Other studies have also shown exams to be traditional and depend on rote learning (Cachia \& Ferrari, 2010; Roy \& Carter, 2013).

Although pupils' disruptive behavior is thought to be an obstacle to creative thinking, some teachers disagreed (35\%). Teachers might not see the problem in the student, but rather in the environment in which the long curriculum and limited time are seen as obstacles.

On the other hand, some teachers seem to lack knowledge of what creative thinking is and what it entails. For example, a large number of teachers (39\%) believed that creative pupils must all be successful. Perhaps teachers think that creativity is somehow related to intelligence, and those who are intelligent are usually successful. This might be because teachers often choose clever pupils for creative activities and competitions, and thus, those clever pupils have a greater opportunity to demonstrate their creativity than others. Added to that, $27 \%$ of teachers' believe that creative thinking is based on the transmission of knowledge. They further believe that creative thinking can develop within the present curriculum, once it is reduced to allow time for creative activities. Indeed, after surveying and observing teachers in England, Turner (2009) found that the length of the curriculum doesn't leave time for pupils to practice creative activities.

Table 4. Primary school EFL teachers' attitudes to creative thinking

\begin{tabular}{|c|c|c|c|c|}
\hline No. & Statement & M & SD & Rank \\
\hline 10 & $\begin{array}{l}\text { Pressure of subject content doesn't leave time for } \\
\text { creative activities. }\end{array}$ & 4.31 & .886 & High \\
\hline 11 & Learning through play increases creativity. & 4.36 & .864 & High \\
\hline 12 & $\begin{array}{l}\text { The creative child is a burden because of his/her } \\
\text { disturbing behavior. }\end{array}$ & 2.96 & .242 & Medium \\
\hline
\end{tabular}




\begin{tabular}{|c|c|c|c|c|}
\hline 13 & $\begin{array}{l}\text { We can develop pupils' skills to think in a creative } \\
\text { way with the current curricula. }\end{array}$ & 3.18 & .049 & Medium \\
\hline 14 & Creative pupils are successful. & 3.57 & .028 & Medium \\
\hline 15 & $\begin{array}{l}\text { Creative thinking is based on the transmission of } \\
\text { knowledge. }\end{array}$ & 2.98 & .200 & Medium \\
\hline 16 & $\begin{array}{l}\text { Individual assignments based on problem solving } \\
\text { would stimulate creativity. }\end{array}$ & 3.98 & .780 & High \\
\hline 17 & $\begin{array}{l}\text { Content knowledge is not enough; we need critical } \\
\text { thinking \& problem solving skills. }\end{array}$ & 3.95 & .743 & High \\
\hline 18 & $\begin{array}{l}\text { The classroom should be a place where pupils feel } \\
\text { safe and develop self-confidence away from } \\
\text { criticism. }\end{array}$ & 4.44 & .590 & High \\
\hline 19 & $\begin{array}{l}\text { During exams, it is necessary to ask questions that } \\
\text { encourage creative thinking. }\end{array}$ & 4.02 & .836 & High \\
\hline
\end{tabular}

The means and standard deviations were established for teachers' attitudes towards creative thinking according to Table 4.

As to teachers' perceptions of their practice, Table 5 shows a high level of perceptions. However, Statement 21 got the lowest score $(\mathrm{M}=3.75)$, in which a large number of teachers $(36 \%)$ said they sometimes developed pupils' creative thinking skills. This is expected from teachers under pressure from long, time-consuming curricula and traditional written exams that do not allow time for creative thinking. Cachia and Ferrari (2010) reported from an online survey on teachers from 32 countries in Europe that there was a gap between the way teachers understand creativity and the way they say they encourage creativity in their classrooms. They concluded that teachers believe in creative thinking but do not apply it in their classrooms. A possible justification for that could be that most statements are general and appeal to the positive side of teachers, so teachers tended to agree.

Still, more than half the teachers said they always listen to their pupils' questions, which helps to foster creative thinking in pupils (Beghetto, 2007; Pishghadam, Nejad, \& Shayesteh, 2012). Overall, teachers believe that they foster creative thinking, a result that deserves to be examined through classroom observation in order to match teachers' perceptions with their practices, because the literature has reported that teachers often perceive events differently from what actually goes on in the classroom (Al-Nouh, 2008).

Table 5. Primary school EFL teachers' perceptions of their practice

\begin{tabular}{lllll}
\hline No. & Statement & M & SD & Rank \\
\hline 20 & I remind and encourage pupils to be creative. & 4.07 & .741 & High \\
21 & I develop pupils' creative thinking skills. & 3.75 & .877 & High \\
22 & I encourage pupils to question \& think independently. & 4.12 & .807 & High \\
23 & I listen to pupils when they ask questions. & 4.53 & .581 & High \\
24 & During discussion, I ask pupils questions to encourage them to think & 4.29 & .666 & High \\
& deeply about the topic. & & & \\
25 & I urge pupils to tell me about what they have learned by themselves. & 4.05 & .798 & High \\
26 & I push pupils to experiment with what they have learned in varied & 4.17 & .747 & High \\
& situations. & 4.07 & .831 & High \\
27 & I inspire my pupils to find more than one solution to a problem. & 3.91 & .925 & High \\
28 & I prepare questions for my pupils to answer by themselves. & 4.09 & .794 & High \\
\hline
\end{tabular}


The means and standard deviations were established for teachers' perceptions of their practice according to Table 5.

To foster creative thinking in pupils, statement 32 (Table 6) shows almost half the teachers reporting that they always encourage pupils who provide unexpected answers, knowing that they are children, and encouragement might motivate their interest in the lesson. Turner (2009) called it 'thinking outside the box'. On the contrary, in Roy and Carter's study (2013) teachers reported grading only the correct answer. Furthermore, almost half the teachers said that they always used a variety of communication technologies in their classrooms, and Horner and Ryf (2007) asserted that creative teachers foster a learning environment in which there is a range of communication technologies. Likewise, $53 \%$ of the teachers said that they always rewarded originality and creativity. Classroom reward systems would send a message to pupils that their behavior was valued and would encourage them to repeat it. Turner (2009) stated the need to enhance pupils' creativity by rewarding creative thinking, and do Souza (2000) added that teachers should give rewards for creativity and for other assignments as well.

Table 6. Primary school EFL teachers' perceptions of their practice

\begin{tabular}{lllll}
\hline No. & Statement & M & SD & Rank \\
\hline 30 & I allow pupils to exchange ideas \& opinions. & 3.82 & .799 & High \\
31 & I allow pupils to ask about things of interest to them. & 3.89 & .831 & High \\
32 & I praise pupils who provide unexpected answers. & 4.31 & .782 & High \\
33 & I take a boring exercise and turn it into a game. & 4.04 & .776 & High \\
34 & I use a discovery or problem solving approach in teaching pupils. & 3.76 & .819 & High \\
35 & I use a range of communication technologies in my class. & 4.19 & .898 & High \\
36 & I use authentic situations to encourage language use. & 4.26 & .758 & High \\
37 & I reward originality and creativity. & 4.43 & .670 & High \\
38 & I allow pupils to choose their own projects to demonstrate their knowledge. & 4.25 & .816 & High \\
39 & I do not criticize pupils' ideas. & 4.22 & .896 & High \\
\hline
\end{tabular}

The means and standard deviations were established for teachers' perceptions of their practices according to Table 6.

In keeping with the third research question of whether there are differences among teachers based on the different variables, results showed significant differences in teachers' attitudes according to age (Table 7). As expected, old teachers $(41+)$ were less interested in promoting creative thinking in their pupils. This is in line with Cachia and Ferrari's study (2010) that found that teachers younger than 25 years of age developed creativity more readily than older teachers did. As seen in Table 7, the teachers who fostered creativity the most were the youngest teachers (21-30). This variation may be because the oldest teachers seem to prefer teacher-centered approaches and feel that by fostering creativity they lose control of the classroom. Fletcher (2011) pointed out that teachers discourage creativity because they find creative characteristics in children to be distracting and hard to manage. Likewise, Cheung (2012) found in his classroom observation of teachers that classroom control was more important to teachers than creativity.

Table 7. A one-way ANOVA test for primary school EFL teachers' attitudes according to age

\begin{tabular}{llllllll}
\hline No & Part 1 & Variables & N & M & SD & F & Sig. \\
\hline \multirow{3}{*}{1} & \multirow{2}{*}{ Teachers' Attitudes } & $21-30$ & 174 & 3.75 & .375 & & \\
& & $31-40$ & 224 & 3.70 & .402 & 5.099 & .006 \\
& & $41+$ & 36 & 3.53 & .268 & & \\
\hline
\end{tabular}


The means and standard deviations were established for teachers' attitudes according to age as displayed in Table 7.

With respect to teachers' perceptions of their practices, significant differences were detected among teachers according to age (Table 8). Having more positive attitudes, younger teachers might perceive themselves to be fostering creative thinking in their classrooms more successfully than older teachers. Nonetheless, the middle-age teaching group got a higher score compared to the young teachers. It could be that the middle-age teachers are more aware of their practices because they are more experienced and understand that experience helps to improve reflection (Fox, Campbell, \& Hargrove, 2011).

Table 8. A one-way ANOVA test for primary school EFL teachers' perceptions of their practices according to age

\begin{tabular}{llllllll}
\hline No & Part 2 & Variables & N & M & SD & F & Sig. \\
\hline \multirow{4}{*}{1} & Teachers' Perceptions & $21-30$ & 174 & 4.09 & .396 & & \\
& of Practice & $31-40$ & 224 & 4.11 & .439 & 3.981 & .019 \\
& & $41+$ & 36 & 3.89 & .499 & & \\
\hline
\end{tabular}

The means and standard deviations were established for teachers' perceptions of their practices according to age, as displayed in Table 8 .

Regarding the variable of nationality, no significant differences were established for teachers' attitudes towards creative thinking. It seems that all teachers believed that creative thinking was important and played a major role in pupils' future careers. Similarly, Cachia and Ferrari (2010) found that the majority of teachers in Europe believed creativity to be an essential skill that should be nurtured in school. According to Humes (2011), creativity boosts pupils' motivation and strengthens their self-confidence, thus it is seen as an essential skill to be developed throughout the school years and is the responsibility of the teacher.

In line with teachers' attitudes, teachers' perceptions of practice were found to be insignificant factors affecting student creativity. All teachers perceive themselves as fostering creative thinking in the classroom. Still, this needs to be seen. The present study is limited in the fact that it lacked classroom observation which would be useful to check if teachers really do what they think they do. Indeed, Zarillo (2012) reported that researchers have found discrepancy between what teachers' perceive about creative thinking and what they do to develop creative thinking (Cachia \& Ferrari, 2010; Turner, 2013).

However, significant differences were shown in teachers' attitudes based on their majors (Table 9). Significant differences were shown between primary and middle/high school teachers, with the former revealing more positive attitudes towards creative thinking than the latter. It could be that middle/high school teachers were accustomed to teaching adults or older children; thus, they might believe that creative thinking requires higher-order thinking skills relative to older learners (Torrance, 1983, in do Souza, 2000). According to Grainger et al. (2004), as children move through school, their voluntary creativity declines. And Torrance (1983) added that people usually under-evaluate children's ability to think and problem-solve, which has led to a focus on reproducing memorized information and ignoring creative thinking.

Although they lack educational background and pre-service training, the general English teachers scored the highest mean compared to the rest. It could be that the general English teachers understand from their studies of theories in applied linguistics that children have the potential to be creative and have the ability to use their first language creatively (Szerencsi, 2010).

Table 9. A one-way ANOVA test for primary school EFL teachers' attitudes according to major

\begin{tabular}{llllllll}
\hline No & Part 1 & Variables & N & M & SD & F & Sig. \\
\hline \multirow{3}{*}{1} & \multirow{3}{*}{ Teachers' Attitudes } & Primary & 263 & 3.71 & .394 & & \\
& & Middle \& High School & 24 & 3.51 & .342 & 3.480 & .032 \\
& & General English & 146 & 3.74 & .370 & & \\
\hline
\end{tabular}


The means and standard deviations were established for teachers' attitudes with respect to major as displayed in Table 9.

Interestingly, no significant differences were shown for teachers in their perceptions of practice according to major. All teachers said that they fostered creative thinking in their classrooms. However, there is a possibility that teachers ticked what they believed to be the correct answer, rather than what they honestly believed. Unless a classroom observation is made, it is difficult to determine that teachers are actually fostering creative thinking.

Nevertheless, when it came to educational zone, significant differences were shown in teachers' attitudes. According to Table 10, teachers at Mubarak Al-Kabeer educational zone seemed to have more positive attitudes towards creative thinking than the other educational zones. This might be because it is a new educational zone with new modern schools and fewer classes. Also, from teachers' reports, parents hold prominent careers such as engineers and doctors, many of whom push teachers to include more creative activities in the classroom. On the contrary, teachers from Al-Jahra demonstrate the least positive attitudes towards creative thinking. It could be that, unlike Mubarak Al-Kabeer, Al-Jahra is an old educational zone with huge numbers of pupils. Added to that, parents in this zone tend not to be highly educated; in fact, most are illiterate. The difference between the two educational zones is similar to the difference between urban (Mubarak Al-Kabeer) and rural (Al-Jahra) areas.

Table 10. A one-way ANOVA test for primary school EFL teachers attitudes according to educational zone

\begin{tabular}{llllllll}
\hline No & Part1 & Variables & N & M & SD & F & Sig. \\
\hline \multirow{4}{*}{1} & Al-Asema & 68 & 3.62 & .466 & & \\
& Hawalli & 71 & 3.69 & .324 & & \\
& Teachers' Attitudes & Al-Farwaniyah & 81 & 3.69 & .348 & & \\
& & Mubarak Al-Kabeer & 64 & 3.91 & .443 & 6.022 & .000 \\
& Al-Ahmadi & 69 & 3.74 & .288 & & \\
& Al-Jahra & 78 & 3.60 & .361 & & \\
\hline
\end{tabular}

The means and standard deviations were established for teachers' attitudes according to educational zone, as displayed in Table 10.

Regarding teachers' perceptions of practice in relation to educational zone, no significant differences were shown. Interestingly, although results showed no significant differences, teachers at Mubarak Al-Kabeer perceived themselves fostering creative thinking more than the other educational zones, while teachers at Hawalli were the least fostering. Overall, all teachers seemed to believe that they fostered creative thinking in their classrooms.

As to experience, however, significant differences were shown in teachers' attitudes. The results of Table 11 are consistent with the results of Table 7, in which younger teachers showed more positive attitudes towards creative thinking $(\mathrm{M}=3.75)$ compared to older teachers $(\mathrm{M}=3.53)$ and middle-age teachers $(\mathrm{M}=3.70)$. Thus, young and least experienced teachers seem to be the most in favor of creative thinking. Similar results were found in Cachia and Ferrari's (2010) study that reported that teachers who have been teaching for less than a year foster creativity more than others that have taught longer.

Table 11. A one-way ANOVA test for primary school EFL teachers attitudes according to experience

\begin{tabular}{llllllll}
\hline No & Part1 & Variables & N & M & SD & F & Sig. \\
\hline \multirow{3}{*}{1} & \multirow{2}{*}{ Teachers' Attitudes } & 5 years \& less & 143 & 3.80 & .333 & & \\
& & 6-10 years & 218 & 3.66 & .420 & 6.132 & .002 \\
& & 11 years \& more & 70 & 3.65 & .332 & & \\
\hline
\end{tabular}

The means and standard deviations were established for teachers' attitudes according to experience, as displayed in Table 11.

On the other hand, no significant differences were shown for teachers' perceptions of practice based on their 
experience. Nevertheless, the least experienced teachers perceived themselves to be fostering creative thinking more than the middle experienced teachers, and the least fostering of creativity were the most experienced teachers.

As to in-service training, no significant differences were shown for teachers' attitudes. Those who took in-service training $(\mathrm{N}=143)$ and those who didn't $(\mathrm{N}=289)$ seemed to have the same positive attitudes towards creative thinking. This indicates that teachers' attitudes in general are high, which supports the first research question posed at the beginning of this study.

However, teachers' perceptions of practice concerning in-service training showed significant differences as shown in Table 12. Those who took training courses seemed to perceive themselves fostering creative thinking in their classrooms more than those who didn't. Similarly, Cachia and Ferrari (2010), who found a discrepancy between teachers' beliefs and their perceptions of practice, reported that more than half the teachers said creativity was not covered during their in-service training. They concluded that teacher training is essential to foster creativity in education.

Table 12. A one-way ANOVA test for primary school EFL teachers' perception of practice with respect to in-service training

\begin{tabular}{llllllll}
\hline No & Part2 & Variables & $\mathrm{N}$ & $\mathrm{M}$ & $\mathrm{SD}$ & $\mathrm{F}$ & Sig. \\
\hline \multirow{2}{*}{1} & $\begin{array}{l}\text { Teachers' Perceptions } \\
\text { of Practice }\end{array}$ & No Training & 289 & 4.03 & .401 & \multirow{2}{*}{3.392} & .001 \\
& Training & 143 & 4.18 & .473 & & \\
\hline
\end{tabular}

The means and standard deviations were established for teachers' perceptions of practice according to in-service training as displayed in Table 12.

Regarding the two open-ended questions (40 and 41), question 40 requested teachers to select from a number of choices the factors that they believe inhibit creative thinking. They were also provided a space to mention other comments. Results showed lack of time to be the main obstacle preventing creativity, according to the majority of teachers (73.8\%). This is consistent with the literature (do Souza, 2000; Turner, 2013). Lack of training was the second most important obstacle (70.6\%). According to Cachia and Ferrari (2010), educationalists should understand the meaning of creativity, what it entails for education, and how it can be implemented. Traditional teaching methods came third (66.4\%). Similarly, Cheung (2012) found by interviewing teachers that they believed in the factors that foster creative thinking; however, during classroom observation teachers used traditional teaching methods that were teacher-centered and emphasized rote learning. The fourth obstacle was traditional written exams (59.7\%): Pishghadam et al. (2012) noted that creativity was discouraged by testing.

Although lack of resources came last for obstacles to creative-thinking instruction, more than half the teachers believed it plays a role. Another factor reported was the long curriculum (13\%), which was further mentioned by Roy and Carter (2013). Teachers also mentioned that the curriculum was sometimes directed to students above the level of their own pupils. Others mentioned that administrative work added to their workload and thus did not allow time to prepare creative activities. Teachers further reported that the English Inspectorate at the MOE forced them to use uncreative methods and approaches. Other obstacles included the large number of pupils per class (30-35) and parental noncooperation.

Question 41, however, probed deeper into teachers' own practices by asking whether they applied creative-thinking activities in their classes. If the teachers responded "yes", they had to provide an example. From 426 teachers, 269 (i.e., 63.1\%) said they do apply creative thinking activities in their lessons; however, only 63 (i.e., 23.4\%) who said "yes" provided examples. Most activities mentioned follow the criteria of creative activities reported in the literature (Roy, 2013), such as problem-solving, soliciting pupils' opinions, solving puzzles, presenting orally, doing projects, finding endings to stories, brainstorming, and writing in diaries, while only a few were not creative, such as ticking true/false statements, correcting ungrammatical sentences, and matching words with pictures. Rinkevich (2011) noted that teachers often viewed some activities as creative that actually were not, and Roy and Carter (2013) reported from their study that teachers used but $38 \%$ of creative activities in their classrooms. Hence, the researcher of this study wanted to get a better insight into teachers' practices by conducting interviews with teachers and principals.

The first interview question asked principals and teachers whether the current curriculum encouraged creative thinking; the majority (61\%) of principals said it did. Principals believed that the problem was with teachers who 
do not work hard enough and are not motivated. However, all teachers felt that the curriculum was too long and did not leave time for creative activities.

On the other hand, when asked if they believed all pupils to be creative or only some, the majority of the principals $(72.2 \%)$ believed that not all pupils are creative and that it depended on the pupil's level of intelligence. Similarly, more than half the teachers (52\%) believed this too. However, Grainger and Barnes (2006) noted that creativity takes place when humans are actively engaged in an atmosphere of risk and exploration. They believed that creativity included all curricular subjects and all children.

The next question asked principals to report from their classroom observations of teachers whether they used creative-thinking activities in their classes, and most principals (66.6\%) said a few teachers did. Teachers, on the other hand, were asked how they applied creative thinking in their classrooms. Some of the activities reported were games, role-plays, storytelling, riddles, oral presentations, and brainstorming.

When asked to indicate the best environment for creative thinking development, principals reported teacher training to be the most important factor, while teachers reported fully equipped classrooms. However, both agreed that reducing the number of pupils in classes would provide a more suitable environment, including reducing the length of the curriculum, urging parents to cooperate, and having English clubs that encouraged pupils to think "outside the box".

Finally, principals and teachers were asked about the need for training courses in creative thinking. All believed that training courses are essential. Specifically, teachers emphasized the need for more hands-on courses, which they believed to be more beneficial.

In sum, both principals and teachers believed that creative thinking is not encouraged enough, although they gave different reasons for this lapse. Nevertheless, all agreed that training is crucial for the proper application of creative-thinking activities.

Finally, the analysis of exam papers revealed exams to be traditional and emphasizing rote-learning of vocabulary and grammar and the reproduction of factual information. To give an example, in the grammar section, pupils were asked to choose from multiple choices the correct answer.

\section{Conclusion}

According to Soh (2000), teachers perform a central role in promoting and nurturing creativity among their pupils. As seen in this study, teachers' attitudes and perceptions of practice about creative thinking are generally high. However, teachers reported some factors that hindered the proper application of creative thinking in their classrooms, such as time constraints and the long curriculum. As Csikszentmihalyi (1996 in Grainger \& Barnes, 2006) says, if pupils are not given the freedom to ask and experiment with the world around them, then their willingness to think creatively will disappear. One of the main findings of the study is that the younger and less experienced teachers were the most motivated to foster creative thinking. This is consistent with other research studies (Cachia \& Ferrari, 2010). Similarly, those with primary school education had more positive attitudes towards creative thinking than those with middle/high school education. In addition, question 40 revealed time as the major obstacle followed by lack of training courses, traditional teaching methods, traditional written exams, and limited resources; however, question 41 revealed $63.1 \%$ of the teachers saying they did apply creative activities in their lessons.

The interview further revealed that principals often blamed teachers for discouraging creative thinking in pupils, while teachers blamed the long curriculum and time constraints. However, all agreed on the need for in-service training and the provision of resources as well as parents' cooperation.

The main limitation of this study is that it relied mainly on self-reports to collect data. Although using a classroom observation would make the results more reliable, questionnaires make it possible to collect data from a large group of people in a short period of time, and they are more convenient in providing data on attitudes and perceptions. Despite this limitation, the study has contributed some evidence about teachers' attitudes and perceptions of practice towards creative thinking.

Several recommendations emerge: for example, teacher educators can use teachers' reports to plan for a creativity training course with follow up observations to cater for teachers' professional needs. According to Fullan (2001), teachers may value the concept of change but do not know how to translate that into actual practice. Another suggestion would be assigning assistant teachers to give classroom teachers more time to develop creative activities. It is hoped that teachers' concerns will be taken seriously and immediate actions will be taken to pave the way for their professional development. 


\section{Acknowledgements}

Many thanks to the ELT supervisor at the MOE, Dr. Mohamed Mahrous, for supplying me with samples of primary school English exams.

\section{References}

Al-Nouh, N. A. (2008). Are Kuwaiti primary EFL teachers implementing A CLT-based learner-centered method in their classrooms? (Unpublished doctoral dissertation). Newcastle University, Newcastle.

Al-Nouh, N. A. (2014). EFL primary school teachers' attitudes, knowledge and skills in alternative assessment. International Education Studies, 7(5), 68-84. http://dx.doi.org/10.5539/ies.v7n5p68

Beghetto, A. (2005). Does assessment kill student creativity? The Educational Forum, 69, $254-263$. http://dx.doi.org/10.1080/00131720508984694

Beghetto, A. (2007). Does creativity have a place in classroom discussion? Prospective teachers' response preferences. Thinking Skills and Creativity, 2, 1-9. http://dx.doi.org/10.1016/j.tsc.2006.09.002

Beghetto, A., \& Kaufman, C. (2013). Fundamentals of creativity. Educational Leadership: Association for Supervision \& Curriculum Development (ASCD). Retrieved from http://www.ASCD.ORG

Black, P., Harrison, C., Lee, C., Maeshall, B., \& William, D. (2004). Working inside the black box: Assessment for learning in the classroom. The Phi Delta Kappan, 86(1), 8-21.

Brewster, J., Ellis, G., \& Girard, D. (2004). The primary English teacher's guide. Essex, England: Pearson Education Limited.

Cachia, R., \& Ferrari, A. (2010). Creativity in schools: A survey of teachers in Europe. European Commissions. Joint research centre (JRC). Institute for prospective technological studies (ipts). Luxembourg: Publications Office of the European Union.

Cheung, R. (2012). Teaching for creativity: Examining the beliefs of early childhood teachers \& their influence on teaching practices. Australasian Journal of Early Childhood, 37(3), 43-51.

Claxton, F., Pannells, C., \& Rhoads, A. (2005). Developmental trends in the creativity of school-age children. Creativity Research Journal, 17(4), 327-335. http://dx.doi.org/10.1207/s15326934crj1704_4

Constantinides, M. (2010). The art of being creative. A paper presented at the IATEFL, Harrogate Conference, April 2010.

Craft, A. (2000). Creativity across the primary curriculum. London: Routledge.

Craft, A. (2001). An analysis of research and literature on creativity in education. A report prepared for the qualifications and curriculum authority.

Craft, A. (2006). Fostering creativity with wisdom. Cambridge Journal of Education, 36, $337-350$. http://dx.doi.org/10.1080/03057640600865835

Creative Partnerships. (2007). Creativity, culture and education. Retrieved February, 2012, from http://creativitycultureeducation.org/data/files/creative-partnerships-brocchure-3.8pdf

Csikszentmihalyi, M. (1996). Creativity: Flow and the psychology of discovery and invention. New York: Harper.

Dacey, J., \& Lennon, K. (2000). Understanding creativity: The interplay of biological, psychological and social factors. Buffalo, NY: Creative Education Foundation.

Denise do Souza, F. (2000). Teacher \& student perceptions of creativity in the classroom environment. Roeper Review, 22(3), 148-153. http://dx.doi.org/10.1080/02783190009554022

Duffy, B. (2003). Supporting creativity and imagination in the early years. Maidenhead: Open University Press.

ELT General Supervision. (2010). The ELT National Curriculum Statement: Primary Stage. State of Kuwait: Ministry of Education.

Fletcher, L. S. (2011). Creative thinking in schools: Finding the "just right" challenge for students. Gifted Child Today, 34(2), 37-42.

Fox, K., Campbell, M., \& Hargrove, T. (2011). Examining reflective practice: Insights from pre-service teachers, In-service teachers and faculty. Journal of Research in Education, 21(2), 37-54.

Freund, P., \& Holling, H. (2008). Creativity in the classroom: A multilevel analysis investigating the impact of 
creativity and reasoning ability on GPA. Creativity Research Journal, 20(3), 309-318. http://dx.doi.org/10.1080/10400410802278776

Fullan, M. (2001). The new meaning of educational change (3rd ed.). New York: Teachers College Press.

Glaveanu, P. (2011). Creative creativity: Reflections from fieldwork. Integr Psych Pehav, 45, 100-115.

Grainger, T., \& Barnes, J. (2006). Creativity in the primary curriculum. In A. James, T. Grainger, \& D. Wray (Eds.), Learning to teach in the primary school. London, UK: Routledge.

Grainger, T., Barnes, J., \& Scoffham, S. (2004). A creative cocktail: Creative teaching in initial teacher education. Journal of Education for teaching: International Research and Pedagogy, 30(3), 234-253.

Horner, C., \& Ryf, V. (2007). Creative teaching: English in the early years and primary classroom. London \& New York: Routledge Taylor \& Francis Group.

Humes, W. (2011). Creativity and wellbeing in education: Possibilities, tensions and personal journeys. TEAN Journal, 2(1), 1-18.

Ivcevic, Z. (2007). Artistic and everyday creativity: An act-frequency approach. Journal of Creative Behaviour, 41(4), 271-290. http://dx.doi.org/10.1002/j.2162-6057.2007.tb01074.x

Jenkins, W. (2000). The impact of the national curriculum on secondary school science teaching in England and Wales. International Journal of Science Education, 22(3), 325-336. http://dx.doi.org/10.1080/095006900289903

Leung, A. (2008). Teacher concerns about curriculum reform: The case of project learning. The Asia-Pacific Education Researcher, 17, 75-97. http://dx.doi.org/10.3860/taper.v17i1.351

Makel, M. (2009). Help us creativity researchers, you're our only hope. Psychology of Aesthetics, Creativity and the Arts, 3(1), 38-42. http://dx.doi.org/10.1037/a0014919

Mason, H. (2003). The value of creativity: An essay on intellectual history, from Genesis to Nietzsche. Hampshire: Ashgate.

Mumford, D. (2003). Where have we been, where are we going? Taking stock in creativity research. Creativity Research Journal, 15, 107-120. http://dx.doi.org/10.1207/S15326934CRJ152\&3_01

NACCCE (National Advisory Committee on Creative and Cultural Education). (1999). All our futures: Creativity, culture and education. London: DfEE.

Pishghdam, R., Nejad, T., \& Shayesteh, S. (2012). Creativity and its relationship with teacher success. BELT Journal, Porto Alegre, 3(2), 204-216.

Rinkevich, L. (2011). Creative Teaching: Why it matters and where to begin. The clearing house, 84, 219-223.

Roy, J. (2013). Elementary teacher perceptions of teaching practices that foster creative thinking in students. Inquiry, 14, 75-94.

Roy, J., \& Carter, V. (2013). Elementary teacher perceptions of teaching practices that foster creative thinking in students. Inquiry, 14, 75-94.

Schacter, J., Thum, M., \& Zifkin, D. (2006). How much does creative teaching enhance elementary school $\begin{array}{lllll}\text { students' achievement? Journal of Creative Behavior, 40(1), } & \text { 47-72. }\end{array}$ http://dx.doi.org/10.1002/j.2162-6057.2006.tb01266.x

Smears, E., Cronin, S., \& Walsh, B. (2011). A risky business: Creative learning in education. TEAN Journal, 2(1), $1-15$.

Soh, K. (2011). Indexing creativity fostering teacher behavior: A preliminary validation study. The journal of Creative Behavior, 34(2), 118-134. http://dx.doi.org/10.1002/j.2162-6057.2000.tb01205.x

Szerencsi, K. (2010). The need for linguistic creativity in FL classroom discourse. Acta Univeritatis Sapientiae Philologica, 2(2), 286-298.

Torrance, P. (1983). Creativity in the classroom. Washington, DC: National Education Association.

Turner, S. (2009). Novel and engaging versus boring and stagnating: How do pupils and teachers alike perceive the state of creativity in secondary schools? In C. Turgeon (Ed.), Creativity and the child: Interdisciplinary perspectives. Oxford: Inter-Disciplinary Press.

Turner, S. (2013). Teachers' \& pupils' perceptions of creativity across different key stages. Research in 
Education, 89, 23-40. http://dx.doi.org/10.7227/RIE.89.1.3

United Nations Educational, Scientific and Cultural Organization (UNESCO). (2010). World data on education (7th ed.). Retrieved from http://www.ibe.unesco.org/

Wyse, D., \& Spendlove, D. (2007). Partners in creativity: Action research and creative partnerships. Education, 35(2), 181-191.

Zarillo, J. (2012). Teaching elementary social studies: Principles and applications. Boston, MA: Pearson Education Inc.

Zeteroglu, E., Dogan, Y., \& Derman, M. (2012). Determining the opinions of preschool and primary school teacher candidates on creativity and metaphorical perception. Educational Sciences: Theory \& Practice, Special issue, 3135-3152.

\section{Copyrights}

Copyright for this article is retained by the author(s), with first publication rights granted to the journal.

This is an open-access article distributed under the terms and conditions of the Creative Commons Attribution license (http://creativecommons.org/licenses/by/3.0/). 